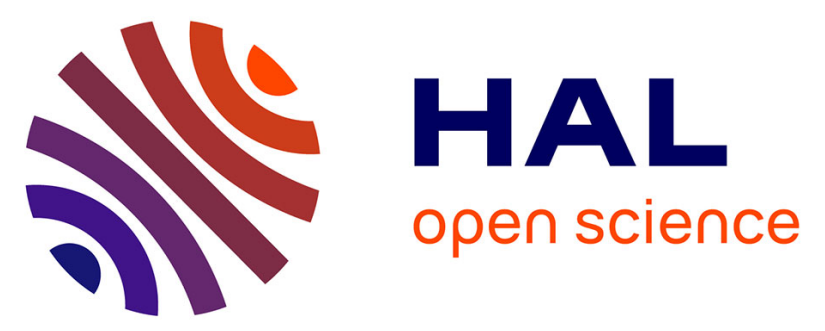

\title{
The INOVE ANR 2010 Blan 0308 project: Integrated approach for observation and control of vehicle dynamics
}

Olivier Sename, Michel Basset, Benjamin Talon, Damien Koenig, John Jairo Martinez Molina

\section{- To cite this version:}

Olivier Sename, Michel Basset, Benjamin Talon, Damien Koenig, John Jairo Martinez Molina. The INOVE ANR 2010 Blan 0308 project: Integrated approach for observation and control of vehicle dynamics. ECC 2014 - 13th European Control Conference, Jun 2014, Strasbourg, France. pp.23402345, 10.1109/ECC.2014.6862364 . hal-01348499

\section{HAL Id: hal-01348499 \\ https://hal.science/hal-01348499}

Submitted on 24 Jul 2016

HAL is a multi-disciplinary open access archive for the deposit and dissemination of scientific research documents, whether they are published or not. The documents may come from teaching and research institutions in France or abroad, or from public or private research centers.
L'archive ouverte pluridisciplinaire HAL, est destinée au dépôt et à la diffusion de documents scientifiques de niveau recherche, publiés ou non, émanant des établissements d'enseignement et de recherche français ou étrangers, des laboratoires publics ou privés. 


\title{
The INOVE ANR 2010 Blan 0308 project: Integrated approach for observation and control of vehicle dynamics
}

\author{
Olivier Sename ${ }^{1}$, Michel Basset ${ }^{2}$, Benjamin Talon ${ }^{3}$, Brigitte d'Andrea-Novel ${ }^{4}$, Damien \\ Koenig ${ }^{1}$ and John Martinez ${ }^{1}$
}

\begin{abstract}
This paper presents the INOVE "Integrated approach for observation and control of vehicle dynamics" project. The aim and organization of the project are described and we present some recent results on the proposed integrated approach to design new methodologies for the improvement of the vehicle dynamical behaviour.
\end{abstract}

\section{INTRODUCTION}

The project is at the heart of the current politics and society concerns in term of road safety. Indeed, even if the number of death due to road accidents is currently decreasing, it is to be noticed that, in Europe, more than 2 million people are injured (about $40 \%$ need a stay in hospital), and almost 90000 people decease each year in road accidents (1.24 Million over the world). From the report of the World Health Organisation [34], together with the improvement of road infrastructures and of transport policies for pedestrians and cyclists, "Safer vehicles" is part of the 5 pillards towards road safety. In particular it is required that Electronic Stability Control should be part of the minimum standards for vehicle construction (ex European and Latin New Car Assessment Programs - NCAP).

The project scientific breakthrough concerns the development of an integrated approach to design new methodologies for the improvement of the vehicle dynamical behaviour. The long-term goal is to equip vehicles with automatic functions for detection and correction of the vehicle dynamics in case of critical situations, in order to improve road safety by decreasing the number and the graveness of the accidents.

To achieve this objective, the challenge in vehicle control design, is the collaboration of all the devices linked to the chassis (such as brakes, suspensions, steering wheels, etc.) in order to control the global behaviour of the vehicle. This motivates many industrial and academic researches in this field, which aims at improving safety and comfort

\footnotetext{
*This work was supported by the French national project INOVE/ ANR 2010 BLAN 0308.

1 O. Sename, D. Koenig and J.Martinez are with GIPSAlab, Control Systems Dept, CNRS-Grenoble INP, 11 rue des Mathématiques, BP 46, F-38402 St Martin d'Hères cedex, France, olivier.sename@gipsa-lab. fr

${ }^{2}$ M. Basset is with MIPS, Unoversité de Haute-Alsace, 12 rue des Frères Lumière, 68093 Mulhouse Cedex, France michel . basset @uha. fr

3 SOBEN S.A.S., Pôle Mécanique d'Alès Cévennes, Vallon de Fontanes, 30520 St-Martin de Valgalgues, France, e-mail: benjamin.talonesoben. fr

4 B. D'Andrea-Novel is with Mines-ParisTech, CAORCentre de Robotique, Mathématiques et systèmes, 60 boulevard Saint-Michel, 75272 Paris cedex 06, France. brigitte.dandrea-novelemines-paristech. fr
}

on commercial cars through the development of integrated control solutions that could handle different driving situations using many different actuators, in a common objective and ensure process reliability. However, in spite of an abundant literature on vehicle dynamics, few studies propose a global approach, taking into account simultaneously modelling, estimation, observation and control aspects. Moreover, the aspects concerning the bias and the uncertainties, that can be linked to the lack of knowledge of some phenomena, to the limit of validity of the models, or to measurement errors, must be handled in a specific way, due to the increasing complexity of the systems.

The core of the project is to elaborate new approaches and innovative solutions, for the identification of the vehicle behaviour, for the observation and detection of critical situations, and for the robust and fault tolerant control of the vehicle dynamics, in view of improving vehicle (and so passengers) safety. The provided methodologies are based on recent results in linear and non linear automatic control.

An unified framework is considered, where some of the key issues to achieve the project objectives are described below.

Modelling/Identification: a unified approach is developed in order to provide, in a generic way, from a reference model whose the structure and the nature have been defined, needed models for observation/control synthesis. The context of global chassis control via switched strategies for mentioned critical driving situations with a serial car (meaning noise on measurement, non linearities, unmodeled characteristics, etc.), is taken into account in order to reach the reference model. First, a new global sensitivity analysis method is developed to focus on principal parameters involved in the modelling. Then, novel model order reduction methodologies are developed with the aim to generate needed models for observers and controllers in a unified way and satisfying to controllability, observability, stability and accuracy aspects compared to existing approaches. The identification of the models are treated with dedicated existing methods.

Observation: we are developing estimation strategies using the on-board sensors available on serial cars such as accelerometers at the center of gravity, odometers for wheel speed measurements, gyrometers for angular velocities as well as radars for vehicle inter-distance. Of course the industrial and real-time context imply that obtained measurements, when available, are noisy. Here, the estimation and filtering strategies rely on recent algebraic methods or parity space approaches. 
Control: new methods for global chassis control are developed, integrating the necessary information given by the observers. This needs advanced control methods for MIMO systems, such as the $H_{\infty}$ approach. In order to account for the actuator coordination and to react against critical situations, some on-line adaptive strategies are proposed, using the Linear Parameter Varying (LPV) framework. A hierarchical control structure is proposed to cope with existing local strategies (ABS), and integrating chassis and longitudinal control. One of the considered key issues is the fault tolerance face to sensors and actuators failures.

For validation, we are interested in some specific critical situations (representative enough to emphasize the project interest) such as:

- Driving on uneven roads, with different road conditions (dry, wet...), with/without braking. Extension in the case of inter-distance control.

- Braking in a (banked or not) curve

- Obstacle avoidance manoeuver (or driving in a curve at high-speed), close to roll-over

\section{TASK 1: MODELLING AND IDENTIFICATION FOR VEHICLE DYNAMICS}

Physical systems are often characterized by reference models of high order, including uncertainties, non linearities or parameter variation. However, for embedded systems (such as integrated driver aid solutions), these models are too complex to be used for observation and control synthesis. Up to now, no direct links exist between the reference models issued of system specifications (e.g. for simulation purpose) and those used for the development of embedded applications. Facing this complexity, engineers involved in the necessary different technical fields, usually develop their own models for each type of application. In the context of futur automatic vehicles integrating unified global chassis control objectives, this usual approach appears too limited, also due to economical constraints (time consuming.

Then, to cope with observation and control requirements, the modeling objectives focus on the identification of a generic reference model, based on a parameters global sensitivity approach, and on the development of novel approaches for model order reduction from linearized ones.

\section{A. Identified Models Base}

Considering previous research works, the MIPS laboratory has developed and identified a non linear reference model including tyres and suspensions non linearities [13]. In order to justify the complexity chosen for the sub-system models (representativness, identifiability), and then, to contribute to the automatic generation of fixed order linearized models, a new method has been developed for parameter sensitivity analysis. Indeed, local and global sensitivity methods, are too restrictive for such a field of applications, considering for example strong constraints on tests trials (constrained excitation), correlated parameters and dynamical aspects. The method, based on chaos polynomials, and has been developed for static models involving correlated parameters

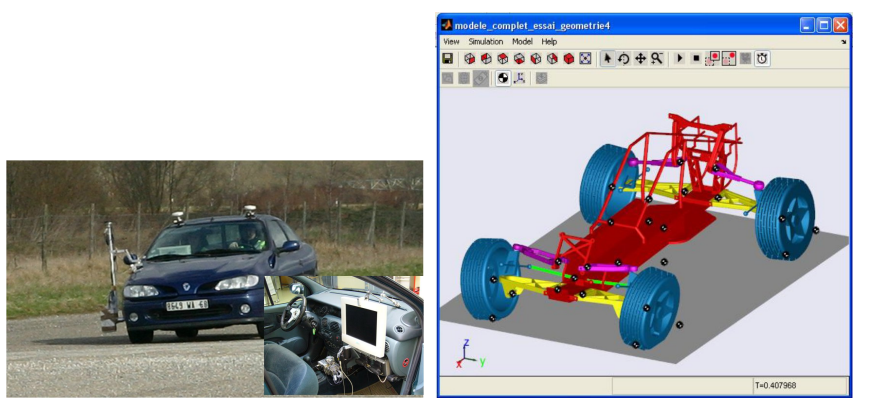

Fig. 1. MIPS test car (left) and INOVE scaled vehicle (right)

and arbitrary probability distribution for input variables. It has been first applied to tyre parameters analysis [15], [13] and is currently applied to damper model analysis in collaboration with GIPSA-Lab. The extension to dynamical models is presented in [14].

On the other hand, a toolbox "Automotive control" has been developed in the project and is maintained in GIPSAlab, which includes different models and control strategies. The vehicle models have been developed and validated in collaboration with the MIPS laboratory (Mulhouse) from experimental data obtained the Renault Mégane Coupé (see figure 1.). Hence, the following models are available in the toolbox, as detailed in [23]:

- Full vehicle non linear model that includes tire models and non linear characteristics of the suspension, in particular a non linear model of a semi-active MagnetoRheological damper.

- Control-oriented models: Vertical 7 DOF model, bicycle model, half front axle model, quarter car

More recently a multi-body model has been developed using the SimMechanics toolbox of Matlab, as illustrated in figure 1.

\section{B. Model order reduction}

The interest of model order-reduction, treated here in a unified way with sensitivity analysis, observation and control developments, is motivated by the fact that high order models generate high order controllers/observers whose synthesis, simulation and implementation is too complex and not reliable.. Both approaches, considering model order reduction (simulation aspect) and robust controller order reduction (implementation of the robust controller) have been investigated, for LTI systems first. It is worth noting that the developed algorithms have to guarantee some specifications such as controllability, observability and stability. Different approaches introducing reachability and observability Grammians of the considered systems, have been developed leading to a balanced truncation model reduction procedure. Such approaches have been tested on different systems as switched systems (considering switched models for observation and control in critical driving situations) [1], [12] and robust controllers to keep performance and regulation considering uncertainties [35]. 


\section{TASK 2: OBSERVATION AND DATA FUSION FOR DETECTION OF CRITICAL SITUATIONS}

Fault Detection, and on-board diagnosis, is of crucial important in dynamical systems, particularly in automotive applications, due to the emergence of new safety systems for vehicles such as anti-lock braking (ABS), adaptive cruise control (ACC), electronic stability control (ESC). Indeed actuator and sensors failures might lead to extremely dangerous situations, that Fault Detection and Diagnosis methods should overcome.

Many model-based fault detection and isolation (FDI) procedures have been developed in the past, as for instance, analytical redundancy-based methods, statistical and geometrical methods or observer-based approaches. More recently, researchers focused on optimization-based techniques for fault detection ( $\mathscr{H}_{\infty}$ and $\mathscr{H}_{-}$based approaches).

Since the vehicle systems are strongly nonlinear, convenient models are Linear Parameter Varying (LPV) ones. This has recently motivated researches on model-based methods for LPV systems.

\section{A. Contribution Fault detection for LPV systems}

Two main contributions have been developed. First, an $\mathscr{H}_{\infty}$ fault estimation method has been developed for LPV systems [29]. Then, parity based residual generation methods for different classes of LPV systems have been studied. The main objective of the parity approach is to design a scheduled parity matrix according to the scheduling parameters and with a robustness face to the uncertainties and unknown inputs. The objective is to minimize the residual sensitivity with respect to uncertainties and disturbances, and maximize its sensitivity face to faults. The approach of the generalized eigenvalues/eigenvectors is used. It results an optimal decoupled parity matrix where the residual synthesis is rewritten in terms of a new optimization problem and solved using Linear Matrix Inequalities (LMIs) techniques. Some of the results, including robustness analysis and implementation are presented in [30]. In the field of fault detection for LPV systems, the major contributions rely in the design of fault indicators for a class of non-linear systems which can be written as LPV Uncertain systems subject to Unknown Inputs, as presented in [28].

\section{B. Detection of critical situations}

Concerning the detection of critical situations, the preliminary work in [32] allows to use the fault detection methodologies in order to detect a critical situations for vehicle lateral dynamics. Indeed the tire model is decomposed in different zones : normal (linear behavior), and critical thus skidding zones (highly non linear). The vehicle model has been rewritten as an LPV one plus a non linear component that accounts for the skidding zone. The fault detection approach consists in detecting this non linear component which is linked to the dangerousness of the situation.

\section{Driving Risk Assessment}

In order to better assess and, then, anticipate potential dangerous driving situations, driving risk assessment based on data fusion, represents an interesting and cost-free way to equip vehicles. But defining driving risk still remains a challenge since the driving task is complex and involves numerous factors of different nature which are not easy to consider for control oriented systems as, for example, sociological factors. In current Intelligent Transportation Systems (ITS), risk estimation is classically performed for a particular situation and with simple arithmetic criteria. The estimated risk (considered as a threshold to define the importance of an action) is generally related to information from either the Vehicle, the Driver or the Environment. To cope with that framework, the developed strategy, based on belief functions which are able to model data imperfections, shows a two-level architecture for relative driving risk assessment considering, simultaneously, several heterogeneous factors linked to the Vehicle-Driver-Environment system. A first level is focused on the determination of a local risk for each entity of the VDE independently from the others. The second fusion level combines the local risks to define the relative risk level (Low, Medium, High) of the driving task. This final risk is determined for driver warning and control anticipation if needed [3], [4].

\section{TASK 3: ROBUST, ADAPTIVE AND FAULT-TOLERANT CONTROL FOR VEHICLE DYNAMIC}

The main objective is here to improve the dynamical behavior of the vehicle during dangerous driving situations. One of the main challenges concerns the coordination between different car subsystems and the available actuators in the today commercial vehicles to keep the desired performance. Here, the performances are achieved if the system guarantees both the car safety (road holding, for instance) and the comfort of passengers. First, some results have been obtained on semi-active suspension control as in [24], [7], [5], [17].

\section{A. Vehicle Dynamics Control}

On the other hand, a global architecture for vehicle dynamics control is proposed considering a full car model (longitudinal, lateral, vertical, roll, pitch, yaw). In terms of control design, we perform an H-inf Multi-Input Multi-Ouput (MIMO) synthesis for gain-scheduled Vehicle Dynamic Control (VDSC) that involves the steering actuators, rear brakes and four active (or semi-active) suspension (see Figure 2), and aims at enhancing the yaw stability and lateral car performances [22], [6].

The aim of this work is to provide an LPV way towards a smart coordination of the three types of actuators, taking into account the physical limitations and some possible loss of effectiveness of braking and suspension actuators [8], [10], [9]. In addition, the proposed technique consider the Actuators structural limitations (like semi-active and saturation limits) in a more explicit way during the control design. This strategy is scheduled by a special monitoring system 


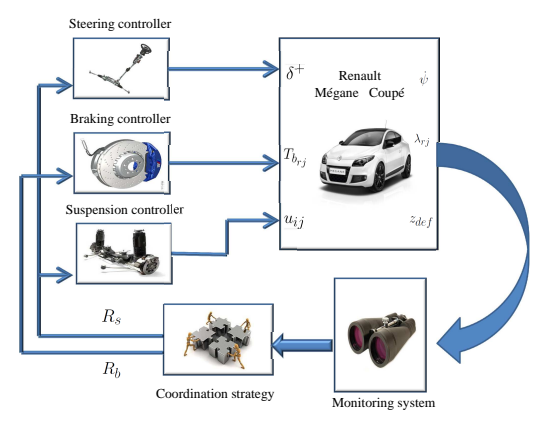

Fig. 2. Global chassis control implementation scheme

defined to evaluate how a driving situation is dangerous and to account for braking/suspension actuator failures. This fault tolerant control structure can handle one actuator failure by changing the configuration of control on line. The whole strategy provides a maximum help to the driver by avoiding accidents during emergency situations. The smart progressive activation of the actuators is the key of performance and safety improvement.

As illustration some simulation results (obtained using our "Automotive toolbox") are shown for a double lane-change maneuver at $100 \mathrm{~km} / \mathrm{h}$ on a wet road (from $t=2 \mathrm{~s}$ to $t=6 \mathrm{~s}$ ). The scenario is as follows:

- Faulty left rear braking actuator: saturation $=75 \mathrm{~N}$

- $5 \mathrm{~cm}$ Road bump from $t=0.5 \mathrm{~s}$ to $t=1.5 \mathrm{~s}$ and from $t=4 \mathrm{~s}$ to $t=5 \mathrm{~s}$ )

- Faulty front left damper: force limitation of $70 \%$

- Lateral wind occurs at vehicle's front generating an undesirable yaw moment (from $t=2.5 \mathrm{~s}$ to $t=3 \mathrm{~s}$ ).

In figure 3 are shown the 3 parameters to activate the braking/steering actuators and coordinate the suspension ones.
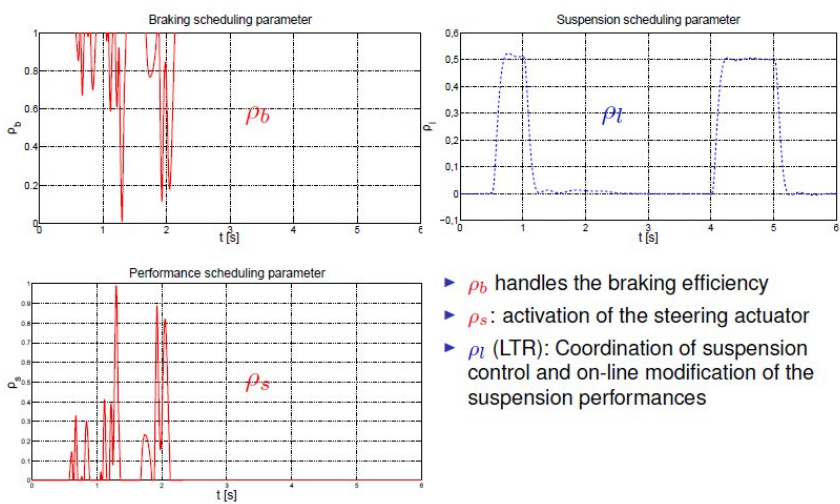

- $\rho_{b}$ handles the braking efficiency

- $\rho_{s}$ : activation of the steering actuator

- $\rho_{l}$ (LTR): Coordination of suspension control and on-line modification of the suspension performances

Fig. 3. Parameter variations for monitoring

The efficient coordination of braking/steering actuators is illustrated in Fig 4, showing that the steering actuator compensate for the faulty braking one.

Finally, as seen in Fig 5, the loss of one damper efficiency is compensated for by the other dampers.

More recent results have been proposed combining non
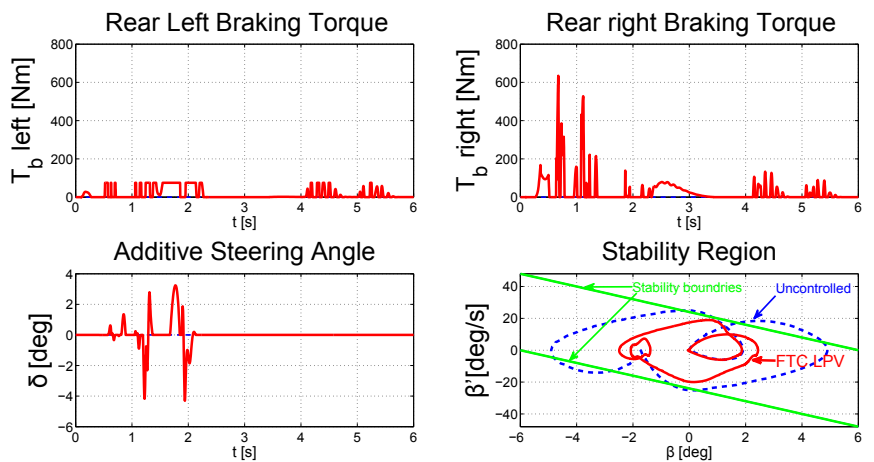

Fig. 4. Actuators activation and vehicle stability analysis

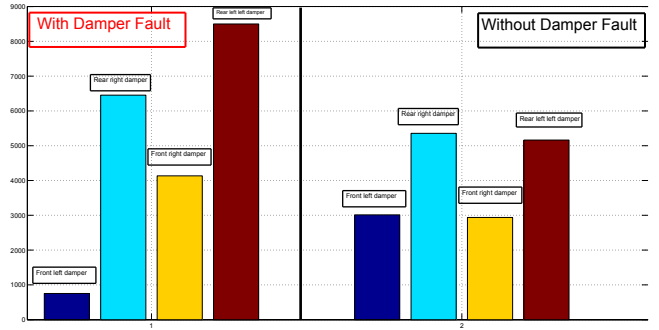

Fig. 5. Suspension control distribution

linear algebraic estimation techniques (for instance to estimate the road profile), together with an LPV suspension control strategy to adapt the performances to the road roughness, as illustrated in Fig 6.

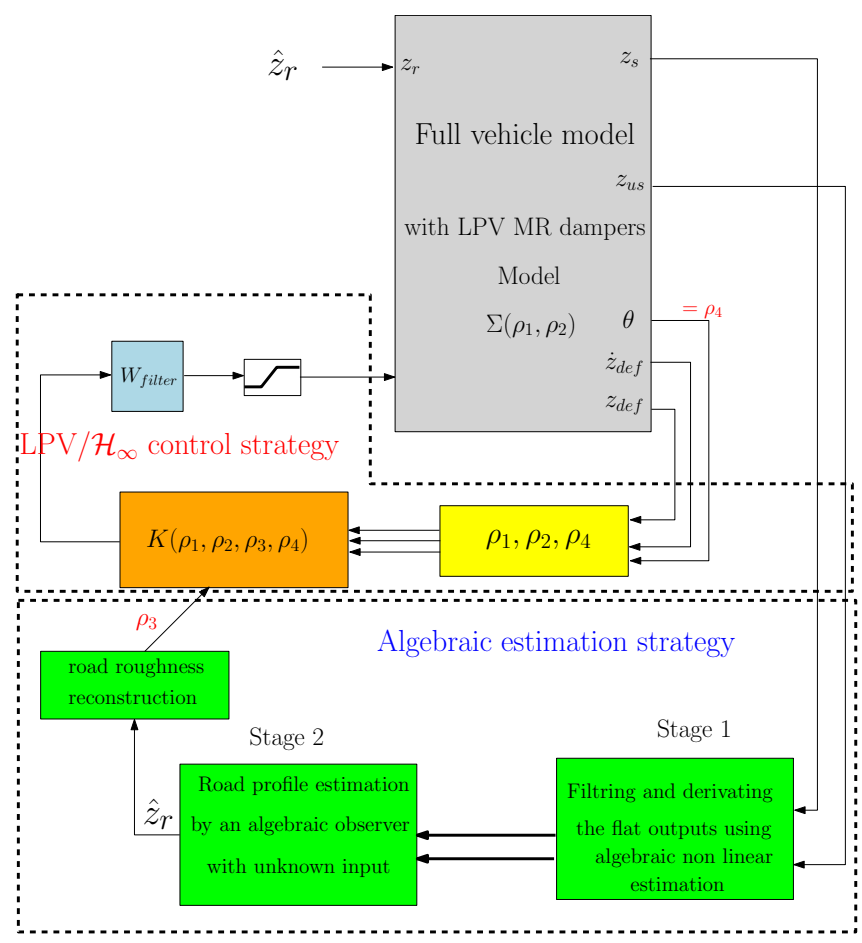

Fig. 6. LPV/Hinf semi-active suspension control strategy with performance adaptation to roll behavior based on non linear algebraic road profile estimation [11] 


\section{B. Fault Tolerant Control}

Due to the number and nature of the available sensors in a car, a multi-sensor fault-tolerant mechanism for LPV systems has been proposed in [18]. The control laws will select at every time-instance, the sensor or a family of sensors that provide the best performance in terms of the control objectives. The latter point allows the control system to avoid faulty sensors in an implicit way. The stability conditions and the sensor switching mechanism is based on the computation of minimal positively invariant sets for linear and polytopic LPV systems.

On the other hand, some methods have been developed in particular when some loss of damper efficiency appears due to oil leakage [26], [27], incorporating, in an LPV framework, a specific parameter for the loss of damping efficiency.

\section{TASK 4: INTEGRATION, VALIDATION AND TESTS.}

\section{A. INOVE Test-bed}

The vehicle dynamics control systems can be evaluated in the 6 degrees-of-freedom: translations in the longitudinal, lateral and vertical axis, as well as the rotation around the roll, pitch and yaw axis. These movements can be controlled using several types of actuators, as : active or semi-active dampers, steering actuators, braking actuators, active differential, .... Among them, the suspension system is the only one that can influence the passenger comfort as well as the car road handling. It is then of huge interest in global chassis control technology. The test rig INOVE, built by SOBEN, aims at studying the effect of the suspension system on the vertical dynamics.

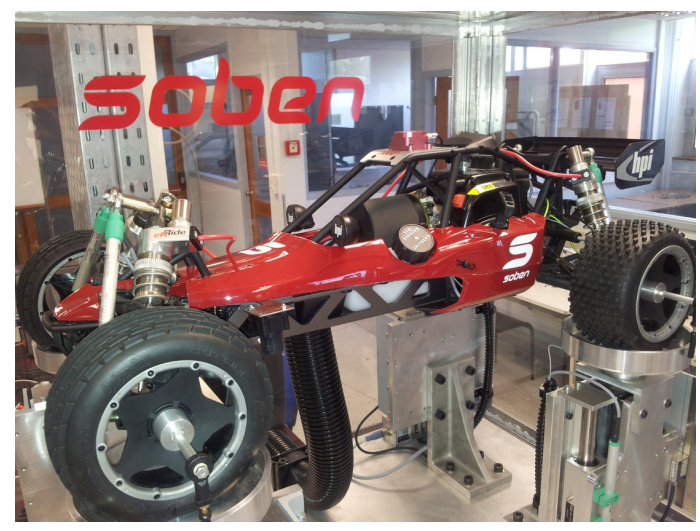

Fig. 7. Test rig

It consists of a 4-poster bench, and a small 1/5 car equipped with 4 semi-active Electro-Rheological dampers (from Fludicon). The road sollicitation are emulated through 4 independent electrical motors, allowing to provide different road profiles under each wheel. Many sensors are used to give informations on the car behavior: an inertial measurement unit, 4 accelerometers for the wheel vertical behaviors, 4 suspension deflection sensors, pitch and yaw angle sensors, 4 force sensors at the tyre/road contact; 4 ER damper force sensors.
The test bench allows to test various strategy on estimation and control for the vertical dynamics, as :

- Modelling : semi-active dampers [17]; 7 DOF vertical dynamics [7]

- Estimation of the road impact and observation of the vertical dynamics state variables [19], [7]

- Detection of sensors and actuators faults using observers and parity equations methods [32]

- Control of semi-active dampers [21], [24]

- Control of the vertical dynamics using Linear Parameter Varying approaches [25]

\section{B. $1 / 5^{\text {th }}$ scale vehicle}

A new prototype has been developed in the framework of INOVE in order to test some Fault Detection approaches. It consists in a $1 / 5^{\text {th }}$ scale vehicle as seen in figure V-B.

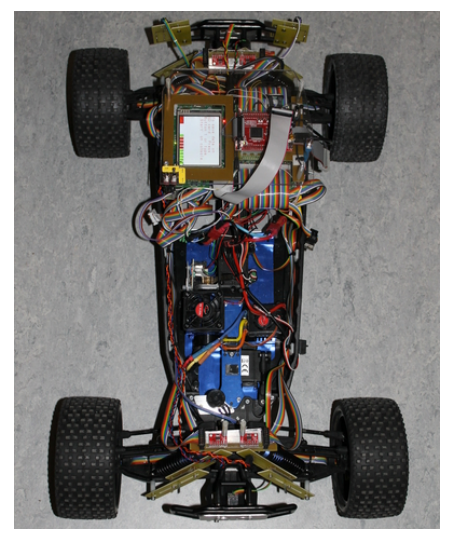

Fig. 8. Prototype with view of the components

This vehicle has 2 actuators: a brushless-motor providing the power to each wheels throw 3 differentials, and a servomotor controlling the steering wheel. It has been equipped with many sensors: deflection sensors in each suspension, 3 axis accelerometers inside each wheel, 3 axis accelerometers in each corner of the chassis (head of the suspension), a 3 axis accelerometer in the center of gravity of the vehicle, a 3 axis gyrometer in the center of gravity of the vehicle, a GPS sensors, a Steering wheel angle sensors, 2 ultrasonic sensors at the front and the rear of the vehicle, a tachometer in the brushless-motor, tachometers inside each wheels.

\section{MIPS test car}

In order to validate the different developments performed in the tasks 1, 2 and 3, the MIPS's Renault Mégane Coupé and Renault Scénic test cars are equiped with differents sensors and actuators (see for example Fig. 1). This phase is the last step in the $\mathrm{V}$ cycle to verify performance and robustness of developments realised. Then, these test cars are complementary of GIPSA-Labs' presented test benches dedicated to HIL tests. These test cars are equiped with sensors to measure in real time vehicle dynamics, driver's activity and road profile. Most of sensors are those ones from commercialised car. Added sensors like precise DGPS matched inertial sensor giving accelerations, speeds and 
trajectory, are used for reference. Moreover, with the Renault Scénic test car, two actuators are mounted on the vehicle to control the longitudinal speed and the steering angle. Considering these equipments, the following developments have been validated or are currently under tests for validation : models, sensitivity analysis, model order reduction, controller order reduction, fault detection, risk assessment, obstacle avoidance, high level control strategy.

\section{REFERENCES}

[1] A. Birouche, B. Mourllion and M. Basset," Model Reduction for Discrete-Time Switched Linear Time-Delay Systems via the $H_{\infty}$ Robust Stability", Control and Intelligent Systems, 39(1), 2011.

[2] A. Birouche, B. Mourllion and M. Basset,"Model order-reduction for discrete-time switched Linear Systems", International Journal of Systems Science (IJSS), Volume 43, Issue 9, September 2012, pages 1753-1763.

[3] J. Daniel, J.-P. Lauffenburger, S. Bernet and M. Basset. " Driving Risk Assessment with Belief Functions. " In Intelligent Vehicles Symposium (IV), Gold Coast, Australia, 26-28 June, 2013.

[4] J. Daniel, J.-P. Lauffenburger and M. Basset. " Multi-criterion Dempster-Shafer Fusion for Speed Limit Determination. " In IFAC World Congress (IFAC WC '11), Milano, Italy, August 28 - September 22011.

[5] A. L. Do, O. Sename, and L. Dugard, "LPV modelling and control of semi-active dampers in automotive systems," in Control of Linear Parameter Varying Systems with Applications, J. Mohammadpour and C. Scherer, Eds. Springer, 2012, ch. 15.

[6] M. Doumiati, O. Sename, L. Dugard, J.-J. Martinez-Molina, P. Gaspar, and Z. Szabo, "Integrated vehicle dynamics control via coordination of active front steering and rear braking," European Journal of Control, vol. 19, no. 2, pp. $121-143,2013$.

[7] Dugard, L.; Sename, O.; Aubouet, S.; Talon, B., "Full vertical car observer design methodology for suspension control applications", Control Engineering Practice, vol 20, Issue 9, pp 832- 845, 2012.

[8] S. Fergani, O. Sename, and L. Dugard, "Performances improvement through an LPV/ $\mathscr{H}_{\infty}$ control coordination strategy involving braking, semi-active suspension and steering systems," in Proceedings of the 51th IEEE Conference on Decision and Control (CDC), Maui, Hawaii, USA, December 2012.

[9] S. Fergani, O. Sename, and L. Dugard, "A new LPV/ $\mathscr{H}_{\infty}$ global chassis control through load transfer distribution and vehicle stability monitoring," in Proceedings of IFAC Joint conference 5th Symposium on System Structure and Control, 11th Workshop on Time-Delay Systems 6th Workshop on Fractional Differentiation and Its Applications, Grenoble, France, February 2013.

[10] S. Fergani, O. Sename, and L. Dugard, "A lpv suspension control with performance adaptation to roll behavior, embedded in a global vehicle dynamic control strategy," in Proceedings of the European Control Conference 2013, Zurich, Switzerland, July 17-19 2013.

[11] Fergani S., Menhour L., Sename O., Dugard L., D’Andréa-Novel B., "A new LPV/Hinf semi-active suspension control strategy with performance adaptation to roll behavior based on non linear algebraic road profile estimation", 52nd IEEE Conference on Decision and Control (CDC 2013), Florence, Italy, December 2013

[12] J. Guillet, B. Mourllion, A. Birouche, M. Basset, "Extracting Second Order Structures from Single-input State-space Models: Application to Model Order Reduction", International Journal of Applied Mathematics and Computer Science (AMCS), Vol 21, nb 3, 2011.

[13] S. Hamza, A. Birouche, F. Anstett-Collin and M. Basset. " Sensitivity analysis for the study of a tire model with correlated parameters and an arbitrary distribution. " In 7th International Conference on Sensitivity Analysis of Model Output, Nice, France, 1-4 July, 2013.

[14] E. Haro Sandoval, F. Anstett-Collin and M. Basset, "Sensitivity study of dynamic systems with polynomial chaos", Journal on Reliability Engineering \& System Safety, Elsevier Eds, in association with the European Safety and Reliability Association, and the Safety Engineering and Risk Analysis Division, 104:15-26, 2012

[15] R. Kiebre, F.Anstett-Collin and M. Basset, "Sensitivity analysis for the study of influential parameters in tyre models", International Journal of Vehicle Systems Modelling and Testing (IJVSMT), Vol. 6, No.1 pp. $72-87,2011$.
[16] R. Kiebre, F.Anstett-Collin and M. Basset, "Using the Magic Formula model for induced longitudinal force at pure lateral slip", International Journal of Vehicle Design (IJVD), Vol. 59, No.4 pp. 305 - 314, 2012

[17] J. Lozoya-Santos, R. Morales-Menendez, R. Ramirez-Mendoza, J.C. Tudón-Martinez, O. Sename, and L. Dugard "Magnetorheological damper: an experimental study", Journal of Intelligent Material Systems and Structures, July 2012 23: 1213-1232

[18] María M. Seron, Xiang W. Zhuo, José A. De Doná, John J. Martínez, Multisensor switching control strategy with fault tolerance guarantees, Automatica, Volume 44, Issue 1, January 2008, Pages 88-97.

[19] L. Menhour, D. Koenig, B. d'Andréa-Novel, Road bank and vehicle roll angles estimation based on functional Switched Proportional Integral Hinf Observer, Proceedings of the 51st IEEE Conference on Decision and Control, December 10-13, Hawaii, 2012.

[20] B. Nemeth, P. Gaspar, J. Bokor, O. Sename, and L. Dugard, "Faulttolerant control design for trajectory tracking in driver assistance systems," in 8th IFAC Symposium on Fault Detection, Supervision and Safety of Technical Processes, 2012, pp. 186-191.

[21] Poussot-Vassal, C.; Spelta, C.; Sename, O.; Savaresi, S.; Dugard, L. "Survey and performance evaluation on some automotive semi-active suspension control methods: A comparative study on a single-corner model", Annual Reviews in Control, Vol 36, Issue 1, pp 148-160, 2012.

[22] C. Poussot-Vassal, O. Sename, L. Dugard, and S. M. Savaresi, "Vehicle dynamic stability improvements through gain-scheduled steering and braking control," Vehicle System Dynamics, vol. 49:10, pp. 1597-1621, March 2011.

[23] C. Poussot-Vassal, O. Sename, L. Dugard, P. Gáspár, Z. Szabó, and J. Bokor, "Attitude and handling improvements through gainscheduled suspensions and brakes control," Control Engineering Practice, vol. 19, no. 3, pp. 252-263, March 2011.

[24] S. Savaresi, C. Poussot-Vassal, C. Spelta, O. Sename, and L. Dugard, Semi-Active Suspension Control Design for Vehicles. Elsevier Butterworth Heinemann, 2010.

[25] O. Sename, P. Gaspar, and J. E. Bokor, Robust Control and Linear Parameter Varying Approaches: application to Vehicle Dynamics, ser. Lecture Notes in Control and Information Sciences. Springer Berlin Heidelberg, 2013, vol. 437.

[26] O. Sename, J-C Tudon-Martinez, and S. Fergani "LPV methods for fault-tolerant vehicle dynamic control", 2nd International Conference on Control and Fault-Tolerant Systems - SysTol, October 9-11, 2013, Nice, France

[27] JC. Tudon Martinez, S.Varrier, O.Sename, R. Morales-Menendez, JJ. Martinez and L. Dugard, "Fault Tolerant Strategy for Semi-Active Suspensions with LPV Accommodation", in 2013 2nd International Conference on Control and Fault Tolerant Systems, October 9-11, 2013, Nice, France

[28] Sébastien Varrier, Damien Koenig, John J. Martinez, Robust fault detection for Uncertain Unknown Inputs LPV system, Control Engineering Practice, Volume 22, January 2014, Pages 125-134.

[29] S. Varrier, C. Vivas-Lopez, J. Lozoya-Santos, D. Koenig, JJ. MartinezMolina and Ruben Morales-Menendez, "Applicative fault tolerant control for semi-active suspension system : Preliminary results", in 12th IEEE European Control Conference, 2013, Zurich, Switzerland.

[30] S.Varrier, D.Koenig and J.Martinez, "Robust fault detection for vehicle lateral dynamics", in 51st IEEE Conference on Decision and Control, pages 4366-4371, 2012. USA, Hawaii, Maui.

[31] S.Varrier, D.Koenig and J.Martinez, "Integrated fault estimation and fault tolerant control design for lpv systems", 5th IFAC SSSC Symposium on System Structure and Control, Grenoble, France, 2013.

[32] S.Varrier, "Détection de situations critiques et commande robuste tolérante aux défauts pour l'automobile", Thèse de doctorat, Université de Grenoble, 2013.

[33] Villagra J., d'Andréa-Novel B. Fliess M. and Mounier H., "A diagnosis-based approach for tire-road forces and maximum friction estimation", Control Engineering Practice, 19, (2011), pp. 174-184

[34] "Global status report on road safety", World Health Organization, ISBN 978924156456 4, 2013.

[35] H. Zebiri, B. Mourllion and M. Basset. " Balanced Truncation Techniques for Active Suspension Reduced-Order Hinf-Controller. " In IFAC Workshop on Advances in Control and Automation Theory for Transportation Applications (ACATTA), Istanbul, Turkey, 16-17 September, 2013. 